\title{
A Study of Radiographic Changes in Endodontically Treated Teeth Restored with Intra-Radicular Posts
}

\author{
Tsvetelina Borisova-Papancheva, Vladimir Panov \\ Department of Conservative Dentistry and Oral \\ Pathology, Faculty of Dental Medicine, Medical \\ University -Varna, Bulgaria
}

\begin{abstract}
The purpose of the study was to evaluate, by examination of periapical radiographs, whether the application of intra-radicular posts in endodontically treated teeth can lead to the development of periapical lesions. A total of 103 panoramic radiographs from 103 patients (263 endodontically treated teeth) from Faculty of Dental Medicine, University of Varna, Bulgaria were investigated. From the 263 teeth evaluated, $58(22 \%)$ had intra-radicular posts. While examining the radiographs a predetermined set of radiographic criteria was included: all teeth should be endodontically treated and have coronal restorations, the intra-radicular posts should be metal cast posts. The success rate for all endodontically treated teeth $(n=58)$ was $70,7 \%$. The following results show that using intra-radicular posts for restoration of endodontically treated teeth do not lead to periapical lesions in the practice where most of the patients were treated. It is most important to perform the coronal restorations carefully in order to avoid coronal microleakage
\end{abstract}

Keywords: intra-radicular posts, microleakage, periapical lesions

\section{Introduction}

The aim of endodontic therapy is to maintain tooth function, and in particular to remove the dental pulp and bacteria, to clean and shape the root canals and to obturate the canals to prevent infection or reinfection (1). The root canal filling materials, which are used nowadays, do not always provide an ideal canal sealing. That is why it is necessary to obtain a well-adapted coronal restoration to protect the apical region against recontamination with oral bacteria (2). A number of studies have reported several types of different restorations $(3,4,5,6)$. Since clinical and laboratory data indicate that teeth are not strengthened 
by posts, their purpose is to retain a core that will provide appropriate support for the definitive crown or prosthesis. Eckerbom et al. examined the radiographs of 200 consecutive patients and radiographically reexamined the same patients 5 to 7 years later to determine the prevalence of apical periodontitis (7). Of the 636 endodontically treated teeth evaluated, 378 (59.4\%) had posts and 258 (40.6\%) did not have posts. At both examinations, apical periodontitis was significantly more common in teeth with posts than in endodontically treated teeth without posts. Turner reported a $12 \%$ absolute rate after a 5 -year retrospective study on teeth having posts and cores (8). Weine et al. reported a $7 \%$ failure rate of 138 posts in service for ten or more years (9). Several studies reported a failure rate of $9 \%$ over certain time period $(10,11,12)$. Goodacre et al. reported a tooth fracture and loss of retention as the two most common causes for fracture (13).

Multiple studies have determined the possible causes of the formation of periapical lesions associated with the roots of endodontically treated teeth that were restored with intra-radicular posts $(6,14,15)$. Zuolo, et al. reported that canal recontamination is increased when the tooth requires post space preparation (16). Grieve et al. have suggested that the preparation of the root canal for the placement of an intra-radicular post may cause displacement of remaining filling material, when this material is insufficient or not well condensed (17). Abramovitz et al. (18) have reported that endodontically treated teeth in which part of the root filling material has been removed have a worse sealing ability than those where the root filling is intact. Another study by Boucher, et al. which evaluated the periapical region of endodontically treated teeth using radiographs, reported that teeth with intra-radicular posts were significantly more associated with periapical lesions than teeth without posts (19). Tronstad et al. (20) found the quality of the coronal restoration to be of significant influence on outcome only when combined with adequate endodontic treatment.

\section{Study Design}

The purpose of the study was to evaluate, by examination of periapical radiographs, whether the application of intra-radicular posts in endodontically treated teeth can lead to the development of periapical lesions.

\section{Matherials and Methods}

This study was undertaken among patients who attended Faculty of Dental Medicine, University of Varna, Bulgaria for an initial examination.

A total of 103 panoramic radiographs from 103 patients (263 endodontically treated teeth) were selected. While examining the radiographs a predetermined set of radiographic criteria was included: all teeth should be endodontically treated and have coronal restorations, the intra-radicular posts should be metal cast posts.

The radiographs were examined on the basis of the following criteria: 1 . Age of the patients -between 19 and 69 years of age. 2. Presence or Absence of Periapical Lesion: score 1 and 2 (according toPAI) $=$ healthy, and score 3, 4 and 5 (according to PAI - Table 1) = diseased 3. Presence or Absence of coronal restoration with a tooth crown 4. Presence or Absence of intra-radicular posts 
Table 1. Periapical index (PAI)

\begin{tabular}{|l|c|}
\hline score & Description \\
\hline $\mathbf{1}$ & Normal periapical structures \\
\hline $\mathbf{2}$ & Small changes in bone structure \\
\hline $\mathbf{3}$ & Changes in bone structure with some mineral loss \\
\hline $\mathbf{4}$ & Periodontitis with well-defined radiolucent area \\
\hline $\mathbf{5}$ & Severe periodontitis with exacerbating features \\
\hline
\end{tabular}

\section{Results}

From the 263 teeth evaluated, $58(22 \%)$ had intra-radicular posts. In the 19 to 29 years old group (1) the total amount of roots with intra-radicular posts was 20 teeth $(19,4 \%)$. In the 30 to 39 years old group (2) the total amount of roots with intra-radicular posts was 23 teeth $(22,3 \%)$. In the 40 to 49 years old group (3) the total amount of roots with intra-radicular posts was 20 teeth $(19,4 \%)$. In the 50 to 59 years old group (4) the total amount of roots with intra-radicular posts was 19 teeth $(18,4 \%)$. In the 60 to 69 years old group (5) the total amount of roots with intra-radicular posts was 21 teeth $(20,4 \%)$ (Table 2).

Furthermore, it is determined that in all of the five groups the percentage of the restored teeth with intraradicular posts is almost the same, with 1 to $3,9 \%$ difference between them.

Table 2. Distribution of intra-radicular posts according to the age of the patients (1-19-29 y.; 2- 3039 y.; 3-40-49 y.; 4- 50-59 y.; 5 - 60-69 y.)

\begin{tabular}{|l|c|c|c|c|c|}
\hline Age & $\mathbf{1}$ & $\mathbf{2}$ & $\mathbf{3}$ & $\mathbf{4}$ & $\mathbf{5}$ \\
\hline $\begin{array}{l}\text { Number of intra- } \\
\text { radicular posts }\end{array}$ & 20 & 23 & 20 & 19 & 21 \\
\hline $\begin{array}{l}\text { Percentage of } \\
\text { intra-radicular } \\
\text { posts }\end{array}$ & $19,4 \%$ & $22,3 \%$ & $19,4 \%$ & $18,4 \%$ & $20,4 \%$ \\
\hline
\end{tabular}

Amongst the total number of 58 teeth with intra-radicular posts, 17 teeth $(29,3 \%)$ had radiological signs of a periapical lesion (PAl>2) (Table 3).

Table 3. Periradicular status in teeth with intra-radicular posts

\begin{tabular}{|c|c|c|c|}
\hline Treatment & Healthy (\%) PAI 1-2 & Diseased (\%) PAI 3-5 & Total number of teeth \\
\hline & 70,7 & 29,3 & \\
\hline Total & 41 & 17 & 58 \\
\hline
\end{tabular}

Table 4 shows the distribution of the types of teeth examined. Maxillary frontal teeth were the types of teeth most frequently restored with posts. $25,9 \%$ of the posts were inserted in the maxillary frontal teeth, $24,1 \%$ - in the maxillary premolars, $22,4 \%$ - in the mandibular molars, $15,5 \%$ in the upper molars, $10,3 \%$ - in the mandibular premolars while only $1,7 \%$ were inserted in the mandibular frontal teeth. 
Table 4. The distribution of the types of teeth with intra-radicular posts restorations

\begin{tabular}{|l|c|c|}
\hline Teeth & Total & $\%$ \\
\hline Maxillary frontal teeth & 15 & 25,9 \\
\hline Maxillary premolars & 14 & 24,1 \\
\hline Maxillary molars & 9 & 15,5 \\
\hline Mandibular frontal teeth & 1 & 1,7 \\
\hline Mandibular premolars & 6 & 10,3 \\
\hline Mandibular molars & 13 & 22,4 \\
\hline
\end{tabular}

From the total amount of 58 teeth with intra-radicular posts, 50 were restored with a tooth crown (Table $5)$.

Table 5. Teeth restored both with intra-radicular posts and crowns

\begin{tabular}{|l|c|c|c|}
\hline & Teeth with crowns & Teeth without crowns & Total number of teeth \\
\hline Number & 50 & 8 & 58 \\
\hline$\%$ & 86,2 & 13,8 & \\
\hline
\end{tabular}

\section{Discussion}

This study was not based on a recall performed on the same patients, so there is no possibility to compare pre- and post-panoramic X-rays. Some of the patients might have visited the Department because of dental problems that is why some of the results might not be representative.

A number of surveys reported about failure rates between $7-12 \%(8,9,10,11,12,22)$. In the present study apical periodontitis was found in $29,3 \%$ of the examined teeth. Moreover the percentage in the youngest group of age 19 to 29 years old $(19,4 \%)$ is the same as the one in the group of age range for 40 to 49 years old. Only $1 \%$ more $(20,4 \%)$ intra-radicular posts are inserted in the oldest group of age from 60 to 69 years old.

The results from this survey demonstrate that intra-radicular posts did not represent a significant risk because the sample was relatively small $(n=58)$. Tronstad et al. (20) published a survey based on more comprehensive tooth sample $(n=1001)$ selected according to strict criteria and reached similar conclusions.

Many results based on reports in the current literature have shown that coronal microleakage is the main factor for the failure of endodontic treatment $(23,24,25)$.

Fox et al. (26) concluded that to prevent re-infection of the root canal system, it may be preferable to restore the tooth immediately with a post and composite system rather than place a temporary post crown and subsequently a cast post and core. Moreover, restoration with or without intra-radicular posts should be carefully performed to avoid coronal microleakage at any stage of the restorative treatment. 


\section{Conclusion}

The following results show that using intra-radicular posts for restoration of endodontically treated teeth does not lead to periapical lesions in the practice where most of the patients were treated. It is most important to perform the coronal restorations carefully in order to avoid coronal microleakage.

Maxillary frontal teeth were the types of teeth most frequently restored with posts followed by maxillary premolars and mandibular molars. Mandibular frontal teeth are most rarely restored with intra-radicular posts. It was determined that teeth restored both with intra-radicular posts and crowns are $86,2 \%$.

\section{References}

1. Fonzar F, Fonzar A, Buttolo P, et al. The prognosis of root canal therapy: a 10-year retrospective cohort study on 411 patients with 1175 endodontically treated teeth Europ. J Oral Implant 2009; 2:3:201-208.

2. Tronstad L, Asbjornsen K, Doving L, et al, Influence of coronal restorations on the periapical health of endodontically treated teeth. Endod Dent Traumatol 2000;16:218-221.

3. Abou-Rass M, Donovan TE. The restoration of endodontically treated teeth. J Calif Dent Assoc 1993;21:12:61-67.

4. Manning KE, Yu DC, Yu HC, et al, Factors to consider for predictable post and core build-ups of endodontically treated teeth, Part I: basic theoretical concepts. Restorative Dent 1995;61:8:685688,690,693-695 .

5. Morgano SM, Brackett SE. Foundation restorations in fixed prosthodontics: current knowledge and future needs. J Prosthet Dent 1999;82:6:643-657.

6. Robbins JW. Restoration of the endodontically treated tooth. Dent Clin North Am 2002;46:2:367384.

7. Eckerbom M, Magnusson T, Martinsson T. Prevalence of apical periodontitis, crowned teeth and teeth with posts in a Swedish population. Endodont Dent Traumatol 1991;7:5:214-220.

8. Turner $\mathrm{CH}$. The utilization of roots to carry postretained crowns. J Oral Rehabil 1982;9:193-202.

9. Weine FS, Wax AH, Wenckus CS. Retrospective study of tapered, smooth post systems in place for ten years or more. J Endod 1991;17:293-297.

10. Sorensen JA, Martinoff JF. Clinically significant factors in dowel design. J Prosthet Dent 1984;52: 28-35.

11. Bergman $B$, Lundquist $P$, Sjögren $U$, et al, Restorative and endodontic results after treatment with cast posts and cores. J Prosthet Dent 1989;61:10-15.

12. Torbjörner A, Karlsson S, Ödman PA. Survival rate and failure characteristics for two post designs. J Prosthet Dent 1995;73:439-444.

13. Goodacre CJ, Kan JYK. Restoration of endodontically treated teeth. In: Ingle JI, Bakland LK. Endodontics. BC Decker Inc 2002;913-950.

14. Gish SP, Drake DR, Walton RE, et al. Coronal leakage: bacterial penetration through obturated canals following post preparation. J Am Dent Assoc 1994;125:10:1369-1372.

15. Karapanou V, Cabrera P, Vera J, et al. Effect of immediate and delayed post preparation on apical dye leakage using two different sealers. J Endod 1996; 22:11: 583-585.

16. Zuolo ML, Kato AS, Kherlakian D, et al. Microinfiltração coronária em dentes tratados endodonticamente após preparo do canal protético. Rev Assoc Paul Cir Dent 1996;50:3:253257.

17. Grieve AR, Radford JR. Radiographic observations of posts crowns: some problems and solutions. Dent Update 1995; 22:9: 370-372.

18. Abramovitz L, Lev R, Fuss Z, et al. The unpredictability of seal after post space preparation: a fluid transport study. J Endod 2001; 27:4: 292-295. 
19. Boucher Y, Matossian L, Rilliard F, et al. Radiographic evaluation of the prevalence and technical quality of root canal treatment in a French subpopulation. Int Endod J 2002;35:3:229-238.

20. Tronstad L, Asbjornsen K, Doving L, et al. Influence of coronal restorations on the periapical health of endodontically treated teeth. Endod Dent Traumatol 2000;16:218-221.

21. American Association of Endodontists. Quality assurance guidelines. Chicago: The Association; 1987.

22. Hatzikyriakos AH, Reisis GI, Tsingos N. A 3-year postoperative clinical evaluation of posts and cores beneath existing crowns. J Prosthet Dent 1992;67:454-458

23. Cheung GS. Endodontic failures - changing the approach. Int Endod J1996;46:3:131-138.

24. Friedman S. Treatment outcome and prognosis of endodontic therapy. In: Orstavik D, Pitt Ford TR, editors. Essential endodontology. Publisher:Blackwell 1998 book.

25. Saunders WP, Saunders EM. Coronal leakage as a cause of failure in root canal therapy: a review. Endod Dent Traumatol 1994;10:3:105-108.

26. Fox K, Gutteridge DL. An in vitro study of coronal microleakage in root-canal-treated teeth restored by the post and core technique. Int Endod J 1997;30:6:361-368.

\section{Corresponding author}

Tsvetelina Borisova-Papancheva

Faculty of Dental Medicine, Department of Conservative Dentistry and Oral Pathology, Medical University -Varna

Email: dr borisova@abv.bg 